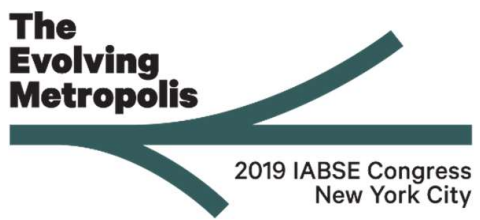

\title{
Predicting the change of hydraulic loads on bridges: a case study in Italy with a 100-year database
}

\author{
Alessandro PUCCI \\ MSc in Structural Engineering \\ University of Minho \\ Guimarães, Portugal \\ alessandro.pucci.engi@gmail.com
}

Graduated "Summa cum Laude" at University of Pisa in February 2019, he is working at University of Minho as researcher.

\author{
Hélder M. SOUSA \\ Postdoctoral researcher \\ University of Minho \\ Guimarães, Portugal \\ sousa.hms@gmail.com
}

Postdoctoral researcher and lecturer at

University of Minho, working on safety assessment and reliability of existing structures.

\author{
José C. MATOS \\ Assistant Professor \\ University of Minho \\ Guimarães, Portugal \\ jmatos@civil.uminho.pt
}

Research fields are asset management systems, LCC, safety assessment, risk evaluation being coordinator of international projects on those topics.

Contact: alessandro.pucci.engi@gmail.com

\section{Abstract}

Planet Earth is naturally subject to climatic variability, but over the recent decades extreme deviations have been observed. Climate change, as a manmade-induced process, is mainly due to the increase of greenhouse gasses emission. Global warming consequences drive also to an intensification of hydrological cycles, leading to more frequent and severe precipitations. In parallel, several bridges have collapsed in the last years due to extreme rainfalls. Although the impacts of climate change on built environment do not always present a direct cause-effect relation, analysis on specific parameters (as rain volume) that are inputs in bridge design, can clarify some aspects of this interaction. In this paper, the peak discharge variation of different rivers located in the northwest of Italy, within the last 100 years, is analyzed. A cluster analysis was performed to understand if the hydraulic design loads should be considered with a different intensity if the bridge had been built with reference to an up-to-date database, or if in the last decades, when the majority of these structures were built. The rainfall data was analyzed through classical techniques, such as the frequency-based statistical method, but without the stationary time hypothesis. In this case, the extreme value theory was used for the estimation of intensity-duration curve parameters. By introducing a second-order analysis, where random variables can change over time, an increase-trend of rainfall height was found, and the peak discharge was determined accordingly. The relevant parameters on the case-study area were preliminarily obtained through geographic information systems. The results evidenced that nowadays-floods parameters are significantly different from those of the past, and this behavior is escalated when high return period values are assumed. Furthermore, although hydraulic design loads are increasing, many existing bridges are not properly maintained, leading to an increased number of collapses.

Keywords: hydraulic loads, bridge design, climate change, predictive hydrology, GIS.

\section{Introduction}

During XX century, an average increase of $0.6^{\circ} \mathrm{C}$ was enough to produce changes on many factors, such as the evaporation-precipitation cycle [1]. The increasing magnitude of rainfalls leads often to severe consequences on the built environment. In particular, bridges are one of the most vulnerable type of structure to the consequences due to variation in rainfall values. Indeed, several cases of collapses due to floods were registered during the last years [2] [3]. To that scope, three main failure mechanisms were then identified: buoyancy, scour 
and dragging [4]. The common denominator though was the inadequacy of structures with respect to hydraulic actions.

This paper aims to highlight the variations in hydraulic actions on bridges due to climate change, and secondly pointing out the importance of prediction models and GIS-based tools in the future design of bridges. The schematic for the proposed framework is given and after applied to a case study regarding a small bridge located in Tuscany, Italy, using a 100-year database information.

\section{Methodology}

\subsection{Small Bridges, big problems}

Recent studies proved that the concentration of short-span bridges is significantly higher than the long-span's ones [4]. Furthermore, the maintenance status of these small infrastructures was found to be poor, accordingly to a recent inspection campaign [5]. Hence, the hydraulic design of short-span bridges is a problem of the outmost importance, as it was demonstrated by the numerous collapses previously cited. While the available information and computing performance are capable to face large-scale analysis [6], big data and global-scale model accuracy can bring new complications to engineers. Then, one of the core problems of design actions is the model scale size.

\subsection{GCMs, RCMs and Extreme Value Theory}

Current solutions to climate change assessment are mainly General Circulation Models (GCM). A key problem with overall literature on GCMs is that they cannot be applied on local-scale due to lack of accuracy [7]. Two systematic approaches have been proposed to fit the global model in a regional context: (i) the development of Regional Climate Models (RCM) and (ii) the downscaling of GCMs through statistical methods. Recent progresses in RCMs have led to high-resolution regional climate change projections such as the EURO-CORDEX [8]. Many experts, as Fikke et. al [9], now contend that rather than using RCM's approach, it might be more useful to engineers to resort to conventional extreme value analysis. Among the mandate $\mathrm{M} / 515$ for the second generation of Eurocodes, Fikke et. al [9] pointed out the deviation of weather parameters from stationary conditions, and therefore the need for analyses of data "at regular intervals (maximum 10 years), according to conventional methods (extreme value theory)" [9].

\subsection{Frequency Analysis in Climate Change}

The aim of Frequency Analysis under a climate change scenario is to set up prediction models for peak discharge evaluation. Since usually there are no hydrometric stations on secondary rivers, the input data is obtained through rain-gauges stations, and the data series are usually stored in hydrological yearbook records. Two pluviometry curves are then built, one corresponding to rain time less than 1 hour, and another to more than 1 hour. The process involved during the first analysis of data is ruled by equation (1), where $t_{1}<t_{2}$, being $h_{i}$ the rain depth occurred in $t_{i}$ rainfall time.

$$
h_{2}: t_{2}=h_{1}: t_{1}
$$

The next step was the choice of the Frequency model. Among the methods used in the extreme value theory, the Gumbel distribution is the most commonly assumed, as it follows with enough accuracy the observed values [10]. Generally speaking, for a given return period $t_{r}$ and a hydrological variable $x$, the Gumbel's formula is displayed in Eq. 2, where, $N, 1 / \alpha$, are the parameters to be found.

$$
x\left(t_{r}\right)=N+\frac{1}{\alpha} y
$$

The calibration can be done using some methods, such as the Maximum Likelihood or the Moments Methods. In this case, it was decided that the best procedure was to apply the Moments Method but removing the hypothesis of stationarity. Indeed, in classical frequency analysis statisticians are used to set two hypotheses [11]: (i) Independence between random variables; (ii) Identically distributed random variables. Observations indicate that the second hypothesis is not anymore acceptable under the ongoing climate changes [12]. In fact, recent evidences have been highlighted a shift in some weather parameters [12], as previously cited, and some authors are now stating that "stationarity is dead" [13]. Despite several authors still affirms that "stationarity is immortal" [14], in the present study 
it was found a clear trend that confirms a significant and stable shift from stationary conditions. The mathematical method for the non-stationary conditions was proposed by Strupczewski et al. [15], where the analysis on the variation of the distribution's first two moments uses either a parabolic or linear regression curve. Equations (3) and (4) show the change in mean and variance accounting time variation. The Gumbel distribution parameters are displayed in equation (5).

$$
\begin{aligned}
& M(t)=M_{0}+M_{1} \cdot t \\
& \sigma(t)=\sigma_{0}+\sigma_{1} \cdot t \\
& \left\{\begin{array}{c}
1 / \alpha(t)=\sqrt{6} \cdot \sigma(t) / \pi \\
N(t)=M(t)-0.57721 \cdot 1 / \alpha(t)
\end{array}\right.
\end{aligned}
$$

It shall be noticed that for each value of time $t$, there will be a different distribution.

\section{Application to the case-study}

The area involved in this research is located in the Northern part of Tuscany, in Italy. Massa and Carrara are the two considered municipalities. As shown in Figure 1, the morphology of the territory is characterized by a rapid transition from a coastal climate to a mountain-high environment within about $10 \mathrm{~km}$. This means a torrential behavior of watercourses characterized by a rather short route.

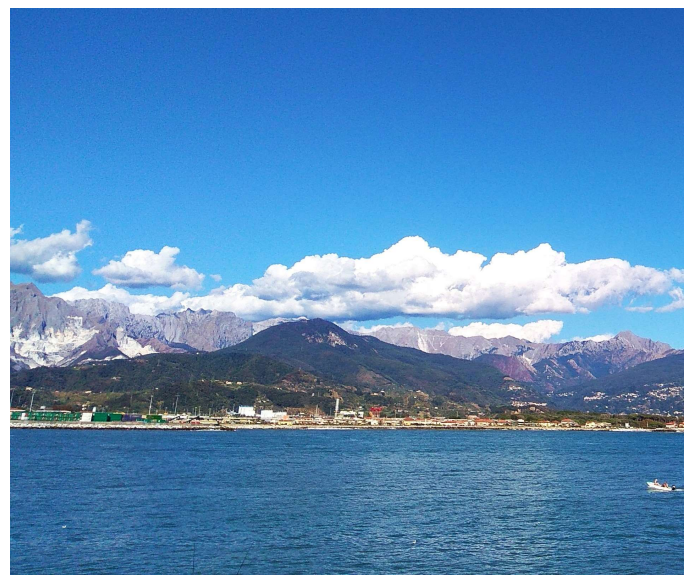

Figure 1. Massa-Carrara and Apuan Alps from sea

\subsection{GIS-aided peak discharge evaluation}

The peak discharge assessment is estimated through the Rational Formula, as in equation (6), where, $\varphi$ is the outlet discharge coefficient, $h$ is the rain depth in [mm], $A$ is the catchment area, $T_{C}$ is the concentration period, whose formulations are widely described in the literature review [10].

$$
Q=0.278 \cdot \varphi \cdot h \cdot A / T_{-} c
$$

This research assessed the peak discharge of the bridge crossing "Torrente Carrione" creek, located on "Via Gino Menconi" (Figure 2). The Bridge on Torrente Carrione was built on 2007, but its hydraulic section is not able to face a peak discharge with return period higher than 20 years [16].

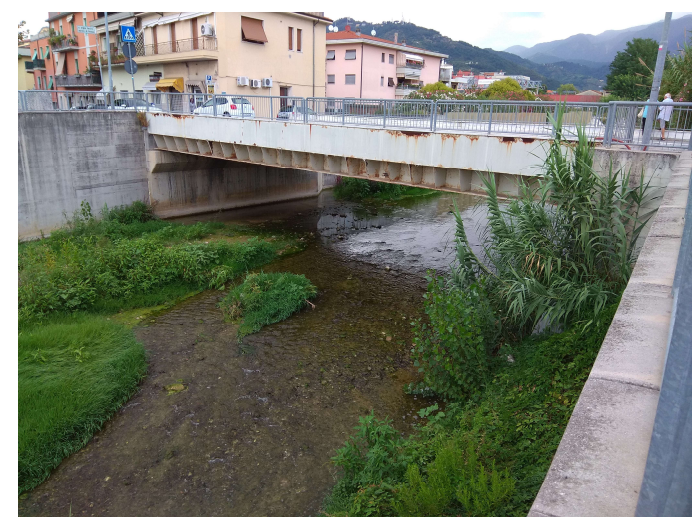

Figure 2. Bridge on "Via Gino Menconi"

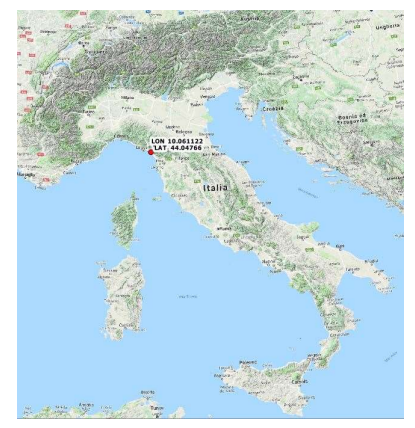

a)

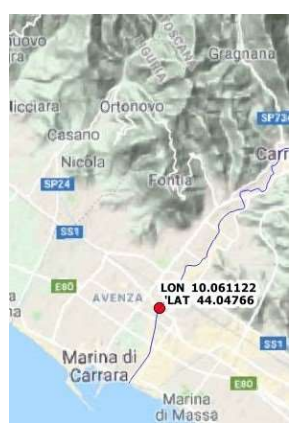

b)
Figure 3. a) General Position of site on Countryscale; b) Coordinates of "Via Menconi" Bridge

Data management analysis was performed using QGIS [17]. In particular, the following parameters were extracted using GIS techniques:

- Catchment area

- Average Curve Number (CN) of the basin

- Calculation of the Hypsographic curve of basins

- Evaluation of the riverbed' slope both upstream and downstream from the bridge. 
The evaluation of $\mathrm{CN}$ is calculated as stated in equation (7), where, $A_{\text {tot }}$ is the catchment area in square $\mathrm{km}$.

$$
C N_{\text {avg }}=\frac{\sum C N_{i} \cdot A_{i}}{A_{\text {tot }}}
$$

\subsection{Peak Discharge and Climate Change}

The peak discharge assessment is estimated through equation (6), introducing the return period inside the rain-depth evaluation. This step is done according to equation (8), where, $y\left(t_{r}\right)$ is the variable of Gumbel's distribution and $t_{r}$ is the action's return period (in years).

$$
y\left(t_{r}\right)=-\ln \left(-\ln \left(1-1 / t_{r}\right)\right)
$$

Then, the rainfall height is evaluated according to the exponential equation (9), where, $a$ and $n$ are calculated using the Least Square Method as shown in equations (10) and (11).

$$
\begin{aligned}
& h\left(t_{r}\right)=a \cdot t^{n} \\
& n=\frac{m \sum_{i=1}^{m}\left(\log t_{i} \cdot \log h_{i}\right)-\sum_{i=1}^{m}\left(\log t_{i}\right) \sum_{i=1}^{m}\left(\log h_{i}\right)}{m \sum_{i=1}^{m}\left(\log ^{2} h_{i}\right)-\left(\sum_{i=1}^{m} \log t_{i}\right)} \\
& a=\frac{\sum_{i=1}^{m}\left(\log ^{2} t_{i}\right) \sum_{i=1}^{m} \log h_{i}-\sum_{i=1}^{m}\left(\log t_{i}\right) \sum_{i=1}^{m}\left(\log t_{i} \log h_{i}\right)}{m \sum_{i=1}^{m}\left(\log ^{2} h_{i}\right)-\left(\sum_{i=1}^{m} \log t_{i}\right)}
\end{aligned}
$$

Then equation (8) is rewritten considering the nonstationary conditions, as shown in equation (12), where, $t_{p}$ is the rain duration.

$$
h\left(t_{r}, t\right)=a(t) \cdot t_{p}^{n(t)}
$$

Resuming, two scenarios were set up for the peak discharge assessment: (i) stationary condition; (ii) non-stationary condition. The difference in peak discharge value represents the impact of climatic stable shift in the considered area.

\section{Results}

The obtained results reveal a high non-stationarity in the average of rain data, as shown in Figure 4. The linear regression obtained was performed also for the $\sigma(t)$, according to equation (3). A linear trend was chosen, because a high coefficient of determination was found. This is confirmed by previous findings [15]. The non-stationarity was considered with data until 2017, and extrapolation up to 2100. Extreme caution must be taken when dealing with predictions, because the forecasted time is not related to the return period of the action. This is well-known to be a statistical concept, and thus, the 1917-2017 interval cannot be assumed to correspond to a 100-year action's return period.

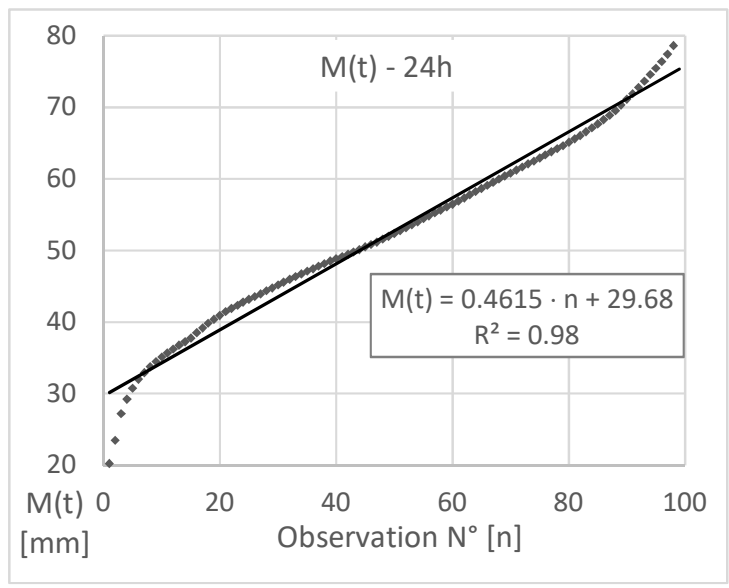

Figure 4. Non-stationarity of mean value

Before assessing the peak discharge variation, an important issue should be considered, as the analyzed bridge is under a redesign process. The new design will increase the structure' safety up to a 30-years return period flood [16]. The peak discharge assessment was performed taking into account the following design values:

$Q_{20}=209 \mathrm{~m}^{3} / \mathrm{s} ; Q_{30}=287 \mathrm{~m}^{3} / \mathrm{s}$

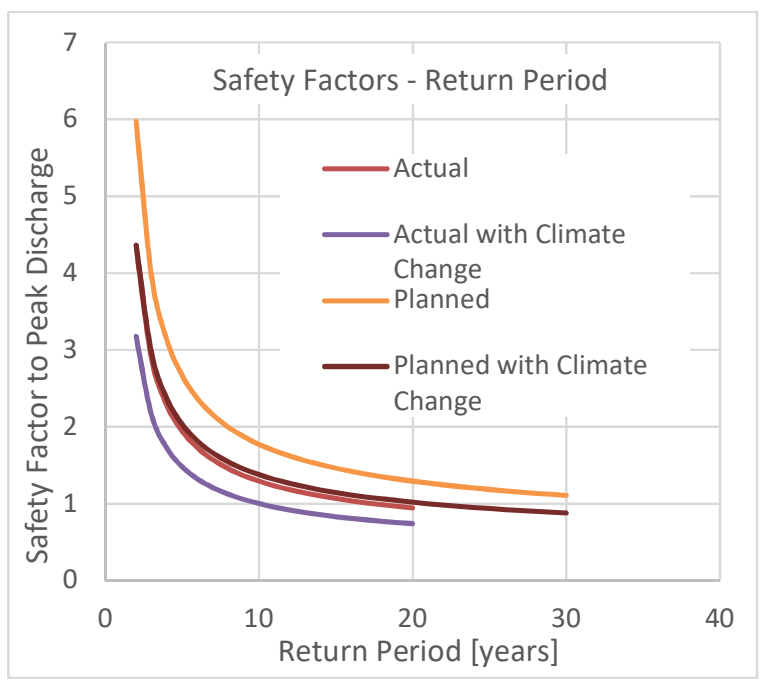

Figure 5. Climate change effect on safety factor 
The design values were compared to the two conditions: actual and planned status. Once the analysis was completed for the design return period, a more detailed evaluation was performed to highlight the overall behavior of the structure when different hydraulic actions occurs. A graph displayed in Figure 5 was built to synthesize the results. In horizontal axis is shown the safety factor evaluated as the ratio between the design peak discharge and the hydraulic action found with the equation (6), in which the return period was included into the rainfall value. There is evidence to suggest the hypothesis that considering the climate change effect would have led to a different design in such case. In fact, the design return period was 30 years, but Figure 5 clearly points out that the changes in safety factors are around $20 \%$ (in the same scenario). More in detail, the planned scenario that refers to the new bridge, has a safety factor of 1.11, while considering the climate change impact, it reduces to 0.88 . Nevertheless, this result is affected by expected uncertainty, since the nonstationary variation was assessed as a mean value in a multiple-scale basin. This is due to the difficulty of collecting so many rain records. However, further data collection would increase the method's reliability, remarking that the proposed framework would not change in its structure.

\section{Conclusions}

This analysis pointed out the need of including climate change impacts in current engineers' practice. The results showed that the expected performance of a new bridge in terms of safety are overestimated, mainly due to a significant shift of rainfall intensity that was observed during the last 100 years. Moreover, the error is found to be in the current models, since they assume hypotheses (as the stationarity of statistical parameters) that are unable to fully represent the interactions of the structure with the physical phenomena of changing actions. This issue mainly concerns the classical extreme value theory. Further experimental investigations on main rivers are needed to estimate the climate change impact directly from hydrometric measures.

\section{Acknowledgements}

This work was partly financed by FEDER funds through the Competitivity Factors Operational Programme - COMPETE and by national funds through FCT Foundation for Science and Technology within the scope of the project POCI-01-0145FEDER-007633.

This project has received funding from the European Union's Horizon 2020 research and innovation programme under grant agreement No 769255. This document reflects only the views of the author(s). Neither the Innovation and Networks Executive Agency (INEA) nor the European Commission is in any way responsible for any use that may be made of the information it contains.

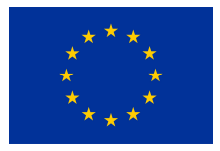

\section{References}

[1] IPCC, "IPCC AR5," 2014. [Online]. Available: https://www.ipcc.ch/assessmentreport/ar5/.

[2] M. L. Puppio and S. Novelli, "The case of Livorno," Des. Civ. Environ. Eng., vol. 46, no. 2016, pp. 190-202, 2018.

[3] D. Ryan, R. Ettema, B. Solan, G. Hamill, and J. McRobert, "Stability of Short-Span Bridges Subject to Overtopping during Floods: Case Studies from UK/Ireland and the USA," $E$ Proceedings 36th IAHR World Congr., pp. 111, 2015.

[4] M. Sassu, L. Giresini, and M. L. Puppio, "Failure scenarios of small bridges in case of extreme rainstorms," Sustain. Resilient Infrastruct., vol. 9689, no. March, pp. 1-9, 2017.

[5] A. Pucci, H. S. Sousa, M. L. Puppio, L. Giresini, J. C. Matos, and M. Sassu, "Method for sustainable large-scale bridge survey.pdf," in Towards a Resilient Built Environment Risk and Asset Management ISBN9783857481635, 2019, pp. 1034-1041.

[6] A. Pucci, "Bridge Network Collapse due to extreme rainstorms," University of Pisa, 2019.

[7] S. Eslamian, Handbook of Engineering Hydrology. Boca Raton, FL 33487-2742: CRC 
2019 IABSE Congress - The Evolving Metropolis

September 4-6, 2019, New York City

Press, 2014.

[8] D. Jacob et al., "EURO-CORDEX : new highresolution climate change projections for European impact research," Reg Env. Chang., vol. 14, no. July, pp. 563-578, 2013.

[9] S. M. Fikke, "How to cope with changes in global climate in standards for actions on structures?," no. June. Brussels, pp. 1-25, 2017.

[10] M. Valerio, Elementi di Idrografia e Idrologia. Pisa, 2016.

[11] J. Beirlant, Y. Goegebeur, J. Segers, J. Teugels, D. De Waal, and C. Ferro, "Statistics of Extremes: Theory and Applications." Wiley, 2004.

[12] P. Meylan, A.-C. Favre, and A. Musy, Predictive Hydrology. Boca Raton, FL 334872742: CRC Press, 2011.

[13] P. C. D. Milly et al., "Stationarity Is Dead: Whither Water Management?," Science (80-. )., vol. 319, no. January, pp. 573-574, 2008.

[14] A. Montanari and D. Koutsoyiannis, "Modeling and mitigating natural hazards: Stationarity is immortal!," Water Resour. Res., vol. 50, no. December, pp. 9748-9756, 2014.

[15] W. G. Strupczewski and Z. Kaczmarek, "Nonstationary approach to at-site flood frequency modelling II. Weighted least squares estimation," J. Hydrol., vol. 248, pp. 143-151, 2001.

[16] R. Toscana, "Lavori di adeguamento statico del Torrente Carrione," 2019. [Online]. Available: http://www.regione.toscana.it//lavori-di-adeguamento-statico-deltorrente-carrione.

[17] QGIS.org, "Quantum GIS." [Online]. Available: https://www.qgis.org/it/site/. 